8. In the "bush" beware of unknown fruit. Some kinds, tempting in appearance, are poisonous in reality.

9. Cleanliness of person and of clothing should be as far as possible observed. The daily use of a tooth-brush and powdered charcoal for the teeth is enjoined. The under clothing should be changed as often as possible, and if it cannot from any cause be washed, it should be hung up in the sun and well shaken.

10. A respirator or veil of thin linen or cotton gauze worn over the face may act as a guard against malaria in the "bush." Vegetable fibre was long ago found to be useful in the West Indies in this way.

11. Never lie down upon the bare ground nor in the thick grass. In the one case you run risk of attack by fever or dysentery, in the other of suakes, scorpions, \&c. Avoid remaining in the vicinity of newly turned-up soil.

12. Do not believe in your own strength, however great it may be, being "proof" against climate. The belief will sooner or later prove delusive. You can lessen the risks and severity of illness by due care and precautions, but the attempt to brave those risks will surely and speedily end in Jour own prostration.

13. The sooner, on being attacked by illness, you consult your medical officer the better your chance of recovery. If you suffer from beadache, dislike to food, pain or sense of coldness in the loins, you are probably about to have an attack of fever. If from gnawing pain, coldness in the stomach, and repeated occasions to visit the rear, you have the early stage of dysentery. In either case medical treatment should be immediately sought.

\section{MOGADOR AS A WINTER RESORT FOR INVALIDS.}

BY ARTHUR LEARED, M.D., F.R C.P., SENIOR PHTSTCIAN TO THE GREAT MORTHBRY HOSPITAL.

TANGIER was recommended in former numbers of THE LANCET as a suitable winter climate for invalids suffering from affections of the lungs. After having visited most of the towns on the Morocco coast, there is one other place where I stayed some weeks, of whose climate I can speak very highly.

The town of Mogador is in latitude $31^{\circ} 30^{\prime} \mathrm{N}$, , or nearly a degree south of Madeira, and its position is very peculiar. It is built partly on rocks and partly on the sandy shore of the Atlantic, in such a way that in certain states of wind and tide the place is surrounded by the sea without being ever flooded. Fully exposed to the cooling and ventilating action of the trade winds, the town is remarkably healthy, notwithstanding imperfect sanitary provisions and the crowded state, in part, of its population of about 14,000 people. M. Beaumier, consul of France, a resident there for a great number of years, has made the climate his special study. He has kindly furnished me with the accompanying abstract of his observations for an entire year (see opposite page).

From the end of November to the commencement of April, but chiefly in February and March, there are copious rains of short duration. They occur when the wind blows from west and south-west. The south wind sometimes blows with great violence, and then occasionally there are thunder storms. Rain at times continues for three or four days together. But, from the notes which M. Beaumier has appended to the above tables, the winter cannot be regarded as wet. All the rainfall of the year occurred on twenty eight days; fourteen of these days were between Jan. 6 th and May 5 th inclusive, and fourteen between October 24th and December 31st inclusive. The days free from rain, therefore, within the period named-in other words, the fine days of winter and spring-numbered 166, against 28 on which rain, on some days only as showers, fell. As a rule, the sky is clear and the climate most enjoyable.

Rain rarely falls during summer and autumn, and they have a remarkably low and uniform temperature. A strong north-east wind then prevails along the coast from Cape Cantin as far as Mogador. At the north of the town there are reefs of rocks, upon which the waves break with great violence. The spray is carried into the town by the wind in the form of pulverised sea-water; and at times people's clothes, hair, and beard become saturated with the saline particles. This is regarded as very healthful, but it has a practical disadvantage: iron rusts, and leather and other articles become mouldy in spite of care. The northeast wind is the great benefactor of the place. When the temperature rises the wind increases in force, after which the thermometer again falls. It begins to blow about 9 A.M., and increases in force until about 3 p Mr., when it gradually decreases until midnight, and from that hour the night is calm.

It is remarkable that the sirocco (S.E. wind), the terrible scourge which is experienced with fatal effects a little inland, is very seldom felt at Mogador. The towns to the north of Cape Cantin, as well as those of the interior, are more or less subject to it. This immunity is explained by the position of Mogador. It is in the latitude of the Great Desert, but is situate far enough towards the west to be outside the range of the S.E. or Desert wind. Places a little farther north are situated in its burning track. On rare occasions a perfect calm, continuing for a day or two, occurs; and this is the worst weather experienced at Mogador. The temperature then may reach $80^{\circ} \mathrm{F}$., and the sky, usually very bright, is overcast; the atmosphere seems thick, and a sense of fatigue and sleepiness is experienced.

There are a few places in the world for which exemption from phthisis is claimed with more or less truth. It is not generally known that Mogador may be added to the number. My friend Dr. Thévenin, who has long practised there, and at whose dispensary (founded by the benevolent Sir Moses Montefiore) I had the best opportunities of seeing the numerous cases which presented, is of opinion that phthisis never originates in the place. Dr. Despine, who preceded Dr. Thévenin, during a residence of thirteen months met with five cases. One was that of a Jew from London; the second was a negro from T'imbuctoo; the third was an Arab from the mountains; and all three were diseased when they came to Mogador: but the two remaining cases he considered to have been locally developed. At all events, as even my own limited experience will allow me to say, the disease must be of extremely rare occurrence. Out of the large number of cases in which I was consulted, or that passed under my inspection, one only, that of a young Jew, presented phthisical symptoms. This gentleman had resided abroad, and his symptoms pointed much more to the results of chronic pneumonia than to those of tubercular phthisis. This is the more remarkable, as in Algiers indigenous phthisis is far from uncommon, and in some parts of Mogador, especially in the Jews' quarter, the factors supposed to be mainly productive of phthisis are in full operation-namely, overcrowded and unventilated dwellings, bad drainage, constant intermarriages, poverty, and food of the worst kind. Can it be that this happy exemption is due to the peculiar saline impregnation of the atmosphere from local causes already described?

A paper appeared in the Marseille Médical, "Mogador et son Climat," par V. Seux, Médecin en Chef des Hôpitaux de Marseille, Professeur à l'École de Médecine, \&c., to which I am indebted for some of the foregoing statements. After having passed in review the advantages and drawbacks of the several climates of Egypt, Algiers, Cannes, Nice, Mentone, Pau, Hyères, Amelie les Bains, Vernet, Venice, Pisa, Rome, Naples, Palermo, Malaga, and Madeira, Dr. Seux expresses an opinion that Mogador will be found superior to all. He says, speaking of phthisis, "Les climats qui conviennent le mieux aux personnes en proie à cette maladie sont ceux où les écarts de température sont les moins fréquents et les moins prononcés; or, il ensemble qu'à ce point de vue, Mogador l'emporte sur toutes les stations connues." Elsewhere he says: "Convaincu que Mogador offrait un climat qui n'avait peutetre pas son egal dans le monde, j'ai cru devoir écrire ce que je savais sur ce pays, comme je l'ai fait pour d'autres sujets, chaque fois que j'ai entrevu la possibilité d'être utile à mes semblables; utile si je puis, telle a toujours été ma devise." This is remarkable testimony in favour of an almost unknown African locality from a man of professional position and experience, himself a resident in the sunny south. My own observations, supported by the statements of M. Beaumier, Dr. Thévenin, and many other residents with whom I have conversed on 
the subject, lead me to endorse all that Dr. Seux has advanced.

Mogador is not so inaccessible nor so remote as the infrequency with which it is visited would lead a stranger to suppose. There is direct communication with London by means of a line of good steamers, sailing monthly, and making the voyage in about a fortnight. Delay is caused on the African coast by the steamers calling at several ports before reaching Mogador. Another mode of reaching it is by the Peninsular and Oriental steamers to Gibraltar, and then crossing to Tangier, at which point English and French steamers call to convey passengers and goods to the southern coast towns.

The accommodation for invalids at Mogador is at present limited. There is no hotel, but a small and comfortable boarding-house is kept by two Jewish ladies. Provisions are good and very cheap; and there are many excellent houses available for visitors if a demand for them existed. The resident physician, Dr. Thévenin, is a gentleman of experience, and held in universal esteem. It may be mentioned that the leading English merchant of the port is, from his own observation, so convinced of the advantages to be derived by invalids at Mogador, that he has most liberally offered to provide house-room free for a limited number of a poor class of patients during the ensuing winter.

The amusements at Mogador are those which the invalid should mainly seek-those of an out-door kind. First, there is the passive enjoyment of a delicious climate, with a sky of such deep blue, and sunsets of such grandeur, Italy can hardly match. There are rides along a firm sandy beach, until at a short distance the country is reached. This is well wooded, varied, and affords good partridge shooting. For those who prefer it, the sea yields abundance of sport in the shape of fish new to the visitor. With all their fauits, the Moors are quick-witted, obliging, and fond of the English. To this brief account much more might be added in favour of Mogador as a health-resort, but space obliges me to conclude.

old Burlington-street.

\section{ON THE}

\section{USE OF THE FORCEPS IN MIDWIFERY.}

\section{BY JAMES MORE, M.D.}

Mr late revered master, Sir James Simpson, in lecturing to his class, used to warn all young accoucheurs against the habit of carrying the forceps with them when called to a labour. This caution, however, arose as much from a laudable desire on his part to restrain the too ambitious interference of the beginner as from any positive belief as to the danger in the application of this instrument.

In one of his most brilliant papers-that on the numerical method of investigation as applied to surgery-he clearly shows the value of statistics in all clinical work; and surely, if they are of any value at all, they are eminently so when applied to the results of the different methods of treating and delivering the parturient female.

No one doubts now that these and similar investigations all point to the one great law (law in the sense of an observed order of facts) that, beyond a given point, the longer the labour the greater the danger to mother and child; and, as a corollary of the above, the longer the labour the more tedious the recovery of the mother.

As has been pointed out of late by two or three writers on this subject, the teaching of the schools is not in accord with the actual practice of many practitioners, both in town and country. We are told in our manuals and by our teachers that the forceps is a perfectly safe instrument, and yet so many obstacles are thrown in the way of its justifiable use that the generality of practitioners look upon it with dread and suspicion, and use it only when they are obliged to do so, and only when the safety of any instrumental interference has been eliminated from the case. That I am not singular in holding this idea is very evident from what Dr. More Madden says in his interesting pamphlet on this subject: "Some years ago the forceps was hardly ever resorted to until the parturient woman, worn out by the protracted sufferings she had endured, was almost moribund, and when, too, the child was probably dead in consequence of the long-continued pressure it had been subjected to. And yet, as I could show you by a reference to the statistics of this hospital (the Rotundo), in forceps cases the mortality to the mother is always less in proportion to the frequency of the operation, as well as to its early performance in those cases which require it."

Keeping in view the law, that the maternal and infantile mortality attendant upon parturition increases in a ratio progressive with the duration of labour, are we not justified nay, are we not bound, to nse every means in our power to shorten that duration; provided always that can be accomplished with safety to the mother and to the child? Many maintain that as long as the head advances, though ever so slowly, instruments should not be employed. Some say, Wait on, leave it to, Nature! And even though the head be stationary or fixed in a position favourable for the use of the forceps, wait, they say, four, six, or even twelve hours before you attempt to deliver the woman from her sore travail.

With all due deference to the mighty ones who have laid the foundations and further advanced the structure of this branch of our art, I humbly enter my protest against any such principle. If it is at all justifiable to assist in the delivery of a breech case, or of the placenta, it must be so to apply the forceps. We help the breech down, and are justified in doing so, in cases where we know Nature could and would ultimately accomplish delivery. We extract the placenta almost immediately after the child is born, and are justified in doing so; yet Nature would, in a large proportion of cases, accomplish this some time within the hour. I have a very high respect for Nature as a vis medicatrix, but, so far as my individual experience goes, she makes a sorry midwife. Why, even among the lower animals, especially those in a state of domestication, we find that unless art step in, the parturient female often fails to bring forth its living offspring. Any shepherd could tell of ewes and lambs lost from causes similar to, if not identical with, those seen in women. Delay with them seems fraught with very decided symptoms. In the mare, too, the average duration of labour is so short that the careful attendant knows well that if his case goes beyond a certain time there is danger. "Is not a cow like a duchess?" She is, and in so far as that the ars obstetrica must come into play in the one as in the other. It is not so with those animals which are, strictly speaking, feral, but with animals which are domesticated, and lead a somewhat artificial life, the act of parturition is fraught with contingent evils, over which mother Nature has little or no control. It may be difficult to say with precision what is a state of nature as regards woman, but we do know that women in the higher circles of life do not, as a rule, represent this ideal. We know also that since the introduction of machinery, more notably the sewing machine, neither the lady in the middle nor the factory girl in the lower class can be looked upon as living under any other than artificial conditions. Nature can, and does, accom. plish much, but she cannot accomplish the delivery of women under conditions as favourable as those brought about by the art of the moderately skilled accoucheur; and simply because, as society is at present constituted, there are introduced into this natural process of parturition adverse conditions, pathological states, and complications, which quite place that process beyond the control of the venerable. mother.

There would seem, then, to be a point of time beyond which danger or unfavourable conditions are apt to manifest themselves; and it may be broadly stated as a fact that labours of six hours' are safer (other things being equal). than labours of twenty-four hours' duration. And Sir Jas. Simpson shows by statistics that the mortality to mother and shild is tenfold greater in labours prolonged beyond thirty-six hours than in labours terminated within the first twenty-four hours.

It is unnecessary to enumerate the complications which may and often do arise in tedious and protracted labour, but these would seem to range themselves under one or other of the following heads :-

1. Danger arising from exhaustion, either of the nerrous, muscular, or circulatory systems.

2. Dangers arising from mechanical pressure. 